\title{
Technologies for Engineering Education
}

\author{
Maclaren $P$. \\ Centre for Learning and Teaching, AUT University, Auckland, New Zealand
}

Singamemni S.

School of Engineering, AUT University, Auckland, New Zealand

Wilson D.I.

School of Engineering, AUT University, Auckland, New Zealand

\begin{abstract}
Within any discipline, teaching involves a distinctive relationship between content, pedagogical approaches and the use of technologies. In engineering education, the content includes mathematical symbolic and diagrammatic forms, traditionally taught using handwritten and talk-based approaches which have not been easily accommodated by keyboard-centric digital technologies. In 2012, a pilot project involving staff in the AUT School of Engineering was initiated to explore the use of digital pen-enabled technologies. This paper reviews educational research supporting the use of these technologies in an engineering education context and reports on findings from the project. The paper also discusses ways of integrating digital penenabled technologies with other developments in educational technology to enhance traditional pedagogical approaches to the teaching of engineering, and to facilitate progressive development of transformative approaches.
\end{abstract}

Keywords: Tablet PC, digital pen-enabled, signature pedagogy

\section{Introduction}

The Engineering profession has its own particular vocabulary and methodologies, with mathematical symbolic and diagrammatic reasoning being of fundamental importance. Engineering education intends to prepare students for participation in the profession of engineering and so also has a distinctive methodology - a characteristic pedagogy. The use of symbolic and diagrammatic approaches is a critical element of this pedagogy.

Shulman [1] used the term 'signature pedagogies' to describe approaches that are specific to an individual profession, in which the development of the core values of the profession are inherent. "Signature pedagogies are important precisely because they are pervasive. They implicitly define what counts as knowledge in a field and how things become known" [1].

The teaching of mathematics, and related applied mathematical disciplines, commonly use a characteristic pedagogical genre, described as "chalk talk" by Artemeva and Fox [2]; this process, where a lecturer demonstrates and articulates problem solving methods on a blackboard or whiteboard while students follow along and take notes, has been a characteristic and embedded component of many engineering programmes. It has become an entrenched because, like signature pedagogies, "once they are learned and internalized, we don't have to think about them; we can think with them" [1].

The chalk talk approach is commonly associated with a lecture-centred educational approach (although it can be a component of other approaches). Lecture-centred approaches have been criticised on a pedagogical basis for their lack of interactivity and limited student engagement [3]. The success of alternative models, such as Problem Based Learning and Project Based Learning, has led to calls for their wider use 
[4,5]. However, significant resources may be required to implement new models that involve an immediate 'paradigm shift', which can constrain their adoption [6].

There are also arguments that not all aspects of entrenched pedagogies are inherently dated and ineffective. Ciccone [7] contends that "signature pedagogies exist because they have proved effective over time". Fox and Artemeva [8] argue that chalk talk "can also be pedagogically interactive, meaningful, and engaging as a way into disciplinary doing and being”. Bergstein [9] discusses factors that can bring a richness to the mathematics lecture.

This project was not conceived with a prior commitment to any particular educational paradigm. Rather, it is concerned with investigating how particular technologies may enhance and transform particular aspects of learning approaches. Shulman [1] argues that changes in external factors related to the profession or within education will disrupt traditional practices; changes in digital technologies for teaching are one such factor.

Mishra and Koehler [10] proposed a framework that identifies Technological, Pedagogical and Content Knowledge (TPCK) as three interrelated components required for successful implementation of new technologies in a learning environment. For this project, the initial focus was on exploring the potential of the technology within an existing pedagogical and content context. Puentedura [11] proposed a model for evaluating the introduction of new technologies against levels of proposed use described as Substitution, Augmentation, Modification or Redefinition (SAMR - see Figure 1); in this model, the project has an initial focus on enhancing existing approaches, rather than on transformative change. Nevertheless, a process of implementing small scale improvements may over time lead to substantive cumulative change, and facilitate more transformative changes in the future.

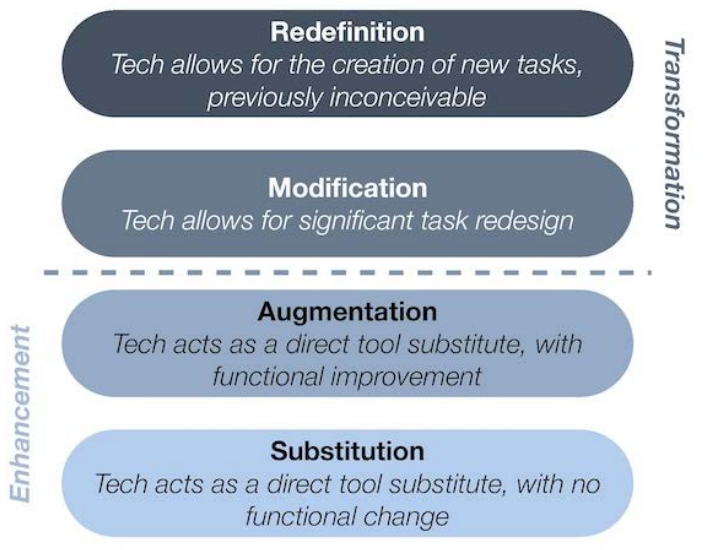

Figure 1: The SAMR Model: Source [11]

Changes in technologies have already influenced traditional pedagogical approaches, but not necessarily with positive outcomes; the effectiveness of PowerPoint has been widely debated [12]. While computers have had an extensive impact on the curriculum and practice of engineering, computers have often served purely as a presentation device within the lecture setting; classrooms and theatres accommodating larger class sizes, and timetabled across the institution for generic disciplines, are often dominated by large projection screens and have limited whiteboard space. In many cases this change in architecture-technology has resulted in a shift from the traditional chalk talk genre, to a genre based on predominantly static PowerPoint slides. This genre limits the capability of the lecturer to demonstrate the reasoning processes underlying mathematical problem solving, and the "pedagogically interactive, meaningful, and engaging” elements of chalk talk are diminished.

\section{Digital Pen Technology}

Digital pen-enabled devices provide the opportunity to return to the exposition of dynamic reasoning processes while maintaining benefits of a digital presentation environment; the lecturer can develop the graphic approach on a smaller scale tablet, while projecting at a large scale; the digital environment allows the lecturer to scroll backward and forward, to zoom to emphasise points, and to switch seamlessly to other software applications. 


\section{Technologies for Engineering Education}

If a computer pen or stylus is to be used to develop mathematical reasoning, it needs to be able to support a natural writing and drawing experience. This requires hardware incorporating an inbuilt digitiser that supports a high degree of resolution and precision. Software also needs to be available to enable material to be effectively generated, displayed and managed.

The Windows Tablet PC was originally introduced in 2002. These early convertiblelaptop computers were ambitious in terms of the capabilities of the technology of the time; early devices had limited battery life, and their heavy weight and expense meant that they did not attract widespread consumer support. Despite continuing improvements in the technology, Tablet PCs have remained a specialised technical tool.

Wacom are a primary supplier of the digitiser technology used in many Tablet PCs. Wacom also produce separate Monitors incorporating digitisers, which can be used with standard desktop computers. Wacom digitisers uses magnetic resonance technology, with a grid embedded under the screen initiating a response in an unpowered stylus. The technology allows high resolution and pressure-sensitive pen input.

The introduction of the iPad in 2010 revolutionised the concept of the mobile computing device. However the iPad is not designed to support high resolution stylus input, and relies on capacitive 'finger' optimised touch for non-keyboard input; this limits its capability as a tool for detailed mathematics. Some Android devices provide digitiser support (e.g. the Samsung S-Pen), but support for digital pens is not integrated across the wider Android environment.

The success of the iPad has prompted a radical shift in Microsoft's Windows OS and tablet strategy. Windows 8, released in October 2012, provides a touch-optimised primary interface. To take advantage of the operating system developments, manufacturers have announced a range of new devices, in various form factors; many higher end models running Windows 8 support stylus digitisers, as well as capacitive touch input and traditional keyboards. Microsoft has for the first time produced its own computer, the Surface tablet, to compete with other manufacturers. These developments are expected to lead to more affordable options for digital pen enabled computing becoming available.

With underlying support for digitiser hardware, and pen-ink capability across the range of MS Office, and third party software, the MS Windows PC environment provides the most comprehensive pen support in both the Operating System (OS) and across applications. It has been widely and successfully used as a teaching tool [13-15], and currently continues to be the most appropriate for the development of a teaching approach incorporating sophisticated handwritten mathematical and diagrammatic material.

\section{The Digital Pen Project.}

The Project was funded by an AUT University LATENT (Learning and Teaching ENabled by Technology) Grant through the Centre for Learning and Teaching. Five HP 2760P Tablet PCs were acquired and allocated to lecturing staff within the School of Engineering.

The Tablet PCs were available to the project staff for classroom use beginning in Semester 2, 2012. Technical hardware support was provided by the university ICT Services. Support for the software and educational use of the devices was provided by a staff member from the Centre for Learning and Teaching with extensive experience in the use of Tablet PCs.

In addition, a Wacom DTU 2231 Monitor [16] was purchased. The Wacom DTU-2231 is a 21.5" widescreen monitor that functions as a standard computer monitor, but has an integrated high precision Wacom pen digitizer. The monitor has a stand that allows the monitor to be tilted between $15^{\circ}$ and 72 ${ }^{0}$ to facilitate writing. It was installed in an 80 seat lecture theatre, running off the lectern Windows PC, connected to a high quality widescreen data projector.

PowerPoint has inbuilt support for pen tools, but the tool capabilities are limited (e.g. line colour can be changed, but not thickness), the 
interface for managing these tools is not immediately accessible, and additional blank slides cannot be added during a session to develop responses to questions. While suitable for annotating existing pre-prepared presentations, the PowerPoint environment was seen as restrictive for chalk talk genre development.

While a range of collaborative software options were possibilities, MS OneNote was adopted by most staff as the primary 'whiteboard' delivery platform for mathematical exposition. OneNote is available as part of the MS Office suite, and provides ready access to a range of digital pen tools. OneNote also has capabilities as a personal and collaborative note taking tool that can be used to advantage in contexts outside the classroom.

\section{Teacher Experiences}

The initial use of the pen-enabled technology was in a context that maintained (or restored) a variant of the chalk talk genre, with discipline content unchanged. While the intent was that staff could concentrate on the technology changes, without requiring significant adaptation to their pedagogical approach, the need for some changes in approach have been noted. Just as presenting on a whiteboard (or chalkboard) requires development of particular skills, presenting via a pen-enabled monitor requires development of workable strategies.

Writing on the small screen of the Tablet PC is not the same as writing on a white board. Some teachers found that considerable adaption was required in planning a lesson, in what to write, where to write and how to write, to maintain the level of presentation that had they had evolved in many years of teaching on a whiteboard.

The change of scale in the writing space does not just require physical adaption in writing dynamics but can result in changes in the dynamics of classroom interaction. Fox and Artemeva [8] described the teaching of mathematics using a traditional chalk or white board as a "cinematic art", with the lecturer as the focus, and many gestures related to the activity directly on the board. When using the Tablet, students are focussed on the large screen, rather than on the lecturer who is primarily involved with the tablet monitor. While the lecturer might emphasise material by highlighting on the tablet, in other instances the lecturer might use gestures in front of, and with direct reference to, the projected screen. The effectiveness of different approaches in this environment is something that lecturers will continue to evaluate.

The larger size of the DTU 2231 Monitor screen allowed writing and drawing at a larger scale than on the Tablet PC and an easier shift of focus between monitor screen and room; however, the placement of the monitor was again lower than optimal and restrained mobility. While the DTU 2231 monitor is available to all staff using the room, the equipping of staff with Tablet PCs is likely to remain a more viable option for accessing pen-enabled technology across a range of locations.

There were also some practical hardware issues in using the Tablet PCs with wired connections. VGA is the standard input mode available for connecting guest computers to data projectors in teaching rooms. However, the VGA Connector on the HP 2760P Tablet is on the bottom edge of the PC when in Tablet mode, and this connector is press-fit and not secured by screws, so easily dislodged. Some staff members resorted to taking the Tablet docking station, which does allow screw-in connection.

While lecturers have traditionally stood during lecture sessions, in most teaching spaces the setup of the teaching lectern or table was not optimised to allow easy writing on the Tablet PC while standing. Further experimentation with different lectern options will continue.

Wireless connection of the tablet display to the data projector obviates issues of data connection and positioning; it allows the lecturer to move independently around the room, with the potential to enhance class engagement. A test of wireless connection using Intel Wireless Display technology [17] was conducted, and while working well in the test environment, current institutional data 


\section{Technologies for Engineering Education}

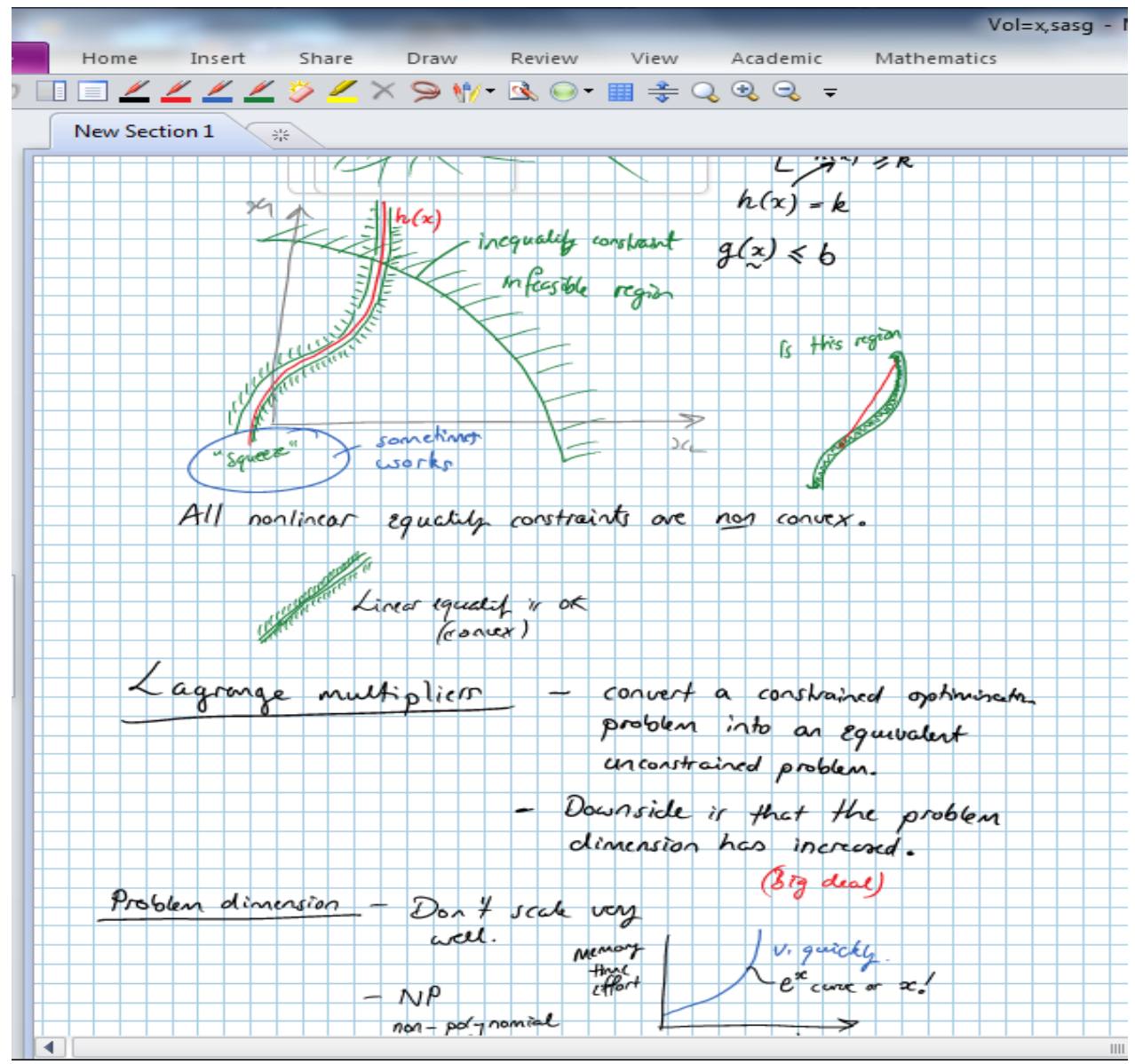

Figure 2: Extract from class notes as developed and projected in class, with a 'dynamic' focused approach.

The development of effective approaches for the use of digital pen technology was seen to be influenced by the nature of the content and level of study of the students, the layout of the teaching space, and the lecturer's own preferences of teaching style. As described by the TPCK model [10], technology, pedagogy and content were closely interrelated.

\section{Student Feedback}

Despite some initial teething problems, the response of students to the use of the Tablet PCs and Wacom monitor was overwhelmingly positive; in informal feedback, students commented on:

- the improved visual clarity of the material, and unobstructed visibility from anywhere in the room (vs whiteboards); improved aural clarity, with the lecturer facing the students, not the board

- their increased engagement with the material, and the lecturer (vs pre-prepared PowerPoint); students see all the steps required/executed, and can review them, and not just see a completed example/answer.

- the benefit in slowing down the lecture and covering the material one step at a time rather than displaying a PowerPoint slide with lots of words which can be hard to follow

- the effectiveness of the approach in facilitating notetaking in conjunction with the lecturer, describing it as encouraging "an active learning approach" 
While students saw some aspects of the 'cinematic nature' of the traditional chalk talk genre $[2,8]$ as changed (perhaps for the better e.g. talking facing students), other key advantages were maintained (e.g. it slows down the "doing"). This suggests that chalk talk can become digital and enhance the learning experience while still maintain the benefits of the genre.

The comments of the students support this use of technology as both technically better and more engaging. This informal feedback echoes the reports from other recent studies of the potential benefits of the use of Tablet PC technology [18-25].

\section{Other Purposes}

The use of Tablet PCs in the marking assignments has also been investigated. Processing of mathematical assignments can be problematic in a digital environment, as student submissions usually generated in a pen-on-paper format. Pilot trials were conducted with students scanning paper assignments to PDF documents, and submitting them online through the institutional Learning Management System (LMS). The Lecturer downloaded the assignments, in bulk or individually, and marked the assignments using software that supports pen annotation (in this case Bluebeam PDF Revu). Annotated PDF assignments are then reuploaded to the LMS, where they are securely available to the students individually through their personal account; this meets privacy requirements while avoiding the time consuming process of physical handback. The pilot trials have proven the viability of the approach and further investigations are planned, including an evaluation of marking software that is integrated with the LMS and allows marking and reuploading of assignments to be completed in a single seamless process. Where assignments are developed digitally, as well as submitted digitally, the process can be entirely paperless, with gains in sustainability.

\section{Developing New Approaches}

The initial investigations in this project have been in existing contexts, using new technology to support 'traditional' pedagogical approaches. In TPCK model terms [10], the changes have been primarily initiated in the Technology Knowledge locus; in SAMR model terms [11], the technology has been used primarily in an enhancement mode, primarily substituting or augmenting existing approaches. It is pertinent to examine how the technology might be used for the transformation of learning. Shulman [1] noted that new technologies, particularly online digital technologies, "create an opportunity for re-examining the fundamental signatures we have so long taken for granted". Potential transformations may be explored as progressive developments from within existing contexts.

While dynamic recordings of pen-enabled mathematics based lectures (or pre-recording of mini-lectures) can be used to enhance traditional approaches, they can also be used to facilitate more transformational approaches. Traditional lecture models involve content delivery during in-class sessions followed by independent review and problem solving exercises out-of-class. In the 'flipped classroom' model, this is reversed; content is delivered online before the class-lecture session, with the class-lecture used for collaborative review of more challenging concepts and problems [26, 27].

Mazur and Couch [28] have documented a pedagogical approach in which peer instruction (PI) is a key component of the lecture sessions in a 'flipped classroom' model. In this approach, peer instruction involves students explaining their interpretation of core concepts within small working groups. The approach has been documented as producing improved understanding of core concepts, as well as increased student engagement [29]; these results are consistent with the benefits proposed by social constructivist theory [30]. Davis [31] references a large number of researchers who have consistently reported that "regardless of the subject matter, students working in small groups tend to learn more of what is taught and retain it longer than when

the same content is presented in other instructional formats. Students who work in collaborative groups also appear more satisfied with their classes”. 


\section{Technologies for Engineering Education}

In the PI model, "students are required to complete the reading on the topics to be covered before class", and complete web based assignments based on these readings, before attending the lecture sessions. For mathematics based disciplines, the use of static texts will not provide the same learning experiences, particularly about process, as provided by a live chalk talk session; however dynamic recordings of chalk talk style expositions can make the benefits of the genre available to the independent learner. The use of screen recording software in conjunction with tablet pen technology provides the capability to generate such resources. Radosevich and Kahn [32] report on how the use of Tablet PC screen recordings "enabled learners to process material more easily", and how the integration of effective technology could enhance the learning environment. Berger [33] noted the value of Tablet PC recordings in providing the "strong visual" component essential in engineering education. The popular success of the Khan Academy [34, 35] also demonstrates the potential of this approach.

The use of classroom communication systems (CCS), commonly described as 'clickers', allow immediate and anonymous feedback from students, and so act as an enabling technology for PI approaches [30]. Online technologies and mobile devices can now offer similar functionality, and these capabilities are an integrated feature of most Tablet PC collaborative software applications.

\section{Students with Tablets}

This project has focussed on equipping the lecturer with a Tablet PC, to explore the benefits of teaching with these devices. A number of institutions have taken a further step, and equipped classrooms, or individual students with Tablet PCs. Significant benefits have been reported from the student use of Tablet PC, including improved student retention, participation in class, and improved results [24, 36, 37].

The capability to record directly in pen on a Tablet PC offers significant advantages for students in mathematical disciplines. Romney [37] notes the difficulty for mathematics students to take notes directly on a standard laptop. Anthony, Yang and Koedinger [38, 39] suggest that handwriting input provides "significant advantages over typing, especially in the mathematics learning domain"; they identify advantages related to a decrease in the extraneous cognitive load, and in "better support for the two-dimensional spatial components of mathematics when compared to existing typing-based tools.” [39, 40]

Some university programmes suggest, or even mandate, students purchase pen-enabled Tablet PCs for their studies. While that is not regarded as a feasible option at AUT at this time, the continuing development of technologies and reduction in costs may see this as an option in the future. There are a range of collaborative software tools that support the use of these tools and enable changes in approaches that further encourage student engagement [41].

\section{Conclusions}

The Digital Pen Project introduced the use of pen-enabled technologies in Engineering, to facilitate the development of mathematical symbolic and diagrammatic reasoning in a digital teaching environment. The use of digitiser tablets with data projectors allowed classroom display of the dynamic development of mathematical reasoning processes in a way that builds on the strengths of traditional teaching approaches. There has been strong positive feedback from students and staff involved, and staff outside the original project and in other departments have expressed interest in using these technologies in their teaching. The adoption of this technology was facilitated as its use evolves naturally within traditional pedagogical approaches. In the longer term, the technology has affordances that can facilitate the development of new innovative approaches.

\section{Acknowledgements}

Thanks to all Project team members and support staff. 


\section{References}

[1] L. S. Shulman, "Signature pedagogies in the professions," Daedalus, vol. 134, no. 3, pp. 52-59, 2005.

[2] N. Artemeva and J. Fox, "The Writings on the Board: The Global and the Local in Teaching Undergraduate Mathematics Through Chalk Talk," Written Communication, Sep. 2011.

[3] P. Armbruster, M. Patel, E. Johnson, and M. Weiss, "Active Learning and Student-centered Pedagogy Improve Student Attitudes and Performance in Introductory Biology," CBE Life Sci Educ, vol. 8, no. 3, pp. 203-213, Sep. 2009.

[4] G. Camp, "Problem-based learning: A paradigm shift or a passing fad?," Medical Education Online, vol. 1, 1996.

[5] J. Rojter, "PBL and Constructivism in Engineering Education," in Proceedings of the 37th Annual SEFI Conference: Attracting Young People to Engineering, TU Delft, Rotterdam, 2009.

[6] S. Singamnemi and A. Jowit, "MovingTowardsProblemBasedLearnin g_AUT.pdf," AIJSTPME-Asian International Journal of Science and Technology in Production and Manufacturing Engineering, vol. 5, no. 1, Mar. 2012.

[7] R. Gurung, N. Chick, and A. Haynie, Eds., Exploring Signature Pedagogies: Approaches to Teaching Disciplinary Habits. Sterling, VA: Stylus, 2009.

[8] J. Fox and Artemeva, "The cinematic art of teaching university mathematics: chalk talk as embodied practice," Multimodal Communication, vol. 1, no. 1, pp. 83-103, Dec. 2011.

[9] C. Bergsten, "Investigating quality of undergraduate mathematics lectures," Mathematics Education Research Journal, vol. 19, no. 3, pp. 48-72, 2007.

[10] P. Mishra and M. Koehler, "Technological pedagogical content knowledge: A framework for teacher knowledge," The Teachers College Record, vol. 108, no. 6, pp. 1017-1054, 2006.
[11] R. Puentedura, "SAMR_ThoughtsForDesign.pdf." Ruben R. Puentedura's Weblog, Sep2012.

[12] A. Savoy, R. W. Proctor, and G. Salvendy, "Information retention from PowerPoint and traditional lectures," Computers \& Education, vol. 52, no. 4, pp. 858-867, May 2009.

[13] E. Ambikairajah, J. Epps, M. Sheng, and B. Celler, "Tablet PC and Electronic Whiteboard Use in Signal Processing Education [DSP Education]," Signal Processing Magazine, IEEE, vol. 24, no. 1, pp. 130-133, 2007.

[14] W. Olivier, "Teaching Mathematics: Tablet PC Technology adds a new dimension," in Proceedings of the 8th International Conference on The Mathematics Education into the 21st Century Project: Reform, revolution and paradigm shifts in mathematics education, 2005, pp. 176-181.

[15] H. Lavery, "Breaking Down Barriers with Tablet Technology for Teaching," Educause Review, Jun-2012. [Online]. Available:

http://www.educause.edu/ero/article/bre aking-down-barriers-tablet-technologyteaching. [Accessed: 03-Sep-2012].

[16] “DTU-2231.” [Online]. Available: http://www.wacom.com/en/businessand-education/products/pendisplays/dtus/dtu-2231. [Accessed: 02Nov-2012].

[17] "Intel ${ }^{\circledR}$ Wireless Display: Your PC Now on Your TV," Intel, 2012. [Online]. Available: http://www.intel.com/content/www/us/e n/architecture-and-technology/intelwireless-display-video.html. [Accessed: 31-Oct-2012].

[18] S. P. Brophy and D. G. Walker, "Case study of the pedagogical impact of tablet PCs as a presentation medium in large-scale engineering classrooms," in Proceedings of the American Society for Engineering Education Annual Conference, 2005.

[19] R. R. Weitz, B. Wachsmuth, and D. Mirliss, "The tablet PC for faculty: A pilot project," JOURNAL OF 
EDUCATIONAL TECHNOLOGYAND SOCIETY, vol. 9, no. 2, p. 68, 2006.

[20] D. Fisher, P. Cornwell, and J. Williams, "Teaching dynamics using interactive tablet PC instruction software," in Frontiers In Education Conference-Global Engineering: Knowledge Without Borders, Opportunities Without Passports, 2007. FIE'07. 37th Annual, 2007, p. S3J-3.

[21] R. Toto, K. Y. Lim, H. Nguyen, S. Zappe, and T. Litzinger, "Acceptance of Tablet PC technology by engineering faculty," in Frontiers in Education Conference, 2008. FIE 2008. 38th Annual, 2008, pp. S4D-7-T1A-12.

[22] Sanson, "Keynote: Why? Are Tablets Superior?," presented at the ATIEC Australasian Tablets in Education Conference, Melbourne, 2009.

[23] W. Xiang, S. Goh, S. Pather, A. Maxwell, $\mathrm{H}$. Wang, and $\mathrm{H}$. Ku, "Use of wireless tablet PCs as an effective learning and teaching enhancement tool," Innovate, Collaborate and Sustain, pp. 1-11, 2009.

[24] C. A. Romney, "Tablet PC use in freshman mathematics classes promotes STEM retention," in Frontiers in Education Conference (FIE), 2011, 2011, pp. F1J-1 -F1J-7.

[25] C. Amelink and G. Scales, "Student use of the Tablet PC: Impact on Student Learning Behaviors," AEE - Advances in Engineering Education - A Journal of Engineering Education Applications, vol. Volume 3, no. 1, 2012.

student attitudes, and impact," Innovate: Journal of Online Education, vol. 4, no. 1, p. n1, 2007.

[34] C. Thompson, "How Khan Academy is changing the rules of education," Wired Magazine, pp. 1-5, 2011.

[35] S. Khan, "Khan Academy," Khan Academy. [Online]. Available: http://www.khanacademy.org. [Accessed: 31-Oct-2012].

[36] S. Millinder, "Positive Impact of a Tablet PC-Based Learning Environment on Student-Perceived Learning Outcomes," in Pen-Based Learning Technologies, 2007. PLT 2007. First
[26] L. Bland, “Applying Flip/Inverted Classroom Model in Electrical Engineering to Establish Life-long Learning,” presented at the 2006 ASEE Annual Conference \& Exposition, 2006.

[27] M. Houston and L. Lin, "Humanizing the Classroom by Flipping the Homework versus Lecture Equation," SITE 2012, vol. 2012, no. 1, pp. 11771182, 2012.

[28] C. H. Crouch and E. Mazur, "Peer Instruction: Ten years of experience and results," American Journal of Physics, vol. 69, no. 9, p. 970, 2001.

[29] C. H. Crouch and E. Mazur, "Peer Instruction: Ten years of experience and results," American Journal of Physics, vol. 69, no. 9, p. 970, 2001.

[30] D. J. Nicol and J. T. Boyle, "Peer instruction versus class-wide discussion in large classes: a comparison of two interaction methods in the wired classroom," Studies in Higher Education, vol. 28, no. 4, pp. 457-473, 2003.

[31] B. G. Davis, Tools for Teaching. John Wiley \& Sons, 2009.

[32] D. Radosevich and P. Kahn, "Using tablet technology and recording software to enhance pedagogy," Innovate Journal of Online Education, vol. 2, no. 6, p. 7, 2006.

[33] E. Berger, "Podcasting in engineering education: A preliminary study of content,

International Workshop on, 2007, pp. 1 $-6$.

[37] C. A. Romney, M. Guo, K. Qian, L. Yang, P. Bhattacharya, Q. X. Phuong, G. Povero, G. Belforte, V. Aravinthan, J. Worden, and others, "Tablet PCs in undergraduate mathematics," in 40th ASEE/IEEE Frontiers in Education Conference, 2010.

[38] L. Anthony, J. Yang, and K. R. Koedinger, "Evaluation of multimodal input for entering mathematical equations on the computer," in CHI'05 extended abstracts on Human factors in computing systems, 2005, pp. 11841187. 
[39] L. Anthony, J. Yang, and K. R. Koedinger, "Towards the Application of a Handwriting Interface for Mathematics Learning," in Towards the Application of a Handwriting Interface for Mathematics Learning, 2006, pp. pp.2077-2080.

[40] L. Anthony, J. Yang, and K. R. Koedinger, "How handwritten input helps students learning algebra equation solving," Retrieved March, vol. 2, p. 2009, 2008.

[41] O. Bonastre, A. P. Benavent, and F. N. Belmonte, "Pedagogical Use of Tablet PC for Active and Collaborative Learning," presented at the 2006 IEEE International Professional Communication Conference, 2006. 